\title{
WORKING TOGETHER TO SUPPORT CHILDREN AND FAMILIES IN DISADVANTAGED COMMUNITIES
}

Caroline Wraith

Senior Policy Analyst

Health Services Policy Branch

\section{Elisabeth Murphy}

Clinical Consultant

Health Services Policy Branch

The Schools as Community Centres Project is an innovative whole-of-government response in NSW to the needs of families with young children living in disadvantaged communities. The project seeks to improve health, welfare and education outcomes for children by ensuring access to appropriate government services.

The link between poverty and adverse social environments and child morbidity has been well documented. ${ }^{1,2,3}$ In Australia 41 per cent of all children aged 0 to 15 years are living in low income families, that is, families who are in receipt of a pension or additional family payment from the Federal Government, and this trend appears to be accelerating. ${ }^{4}$

Evidence shows that children living in families at socioeconomic disadvantage have significantly worse health outcomes and grow into adults who are at greater risk of health problems than their more affluent peers. ${ }^{5}$ Socioeconomically disadvantaged children have:

- higher rates of prematurity and low birth weight

- higher rates of infant mortality

- increased rates of sudden infant death syndrome

- increased rates of accidental and non-accidental injury and death

- lower rates of immunisation

- lower prevalence and duration of breast-feeding

- increased rates of hospitalisation.

Recent evidence suggests that the economic and social stress on families caused by poverty can contribute to the neglect of children, which in turn may leave those children at greater risk of becoming involved in crime. ${ }^{6}$ Research has demonstrated that universal prevention and targeted early intervention programs have been successful in improving health outcomes for children across many of these dimensions. ${ }^{7,8}$
Socioeconomically disadvantaged families also experience barriers when accessing services. Health services, in conjunction with other sectors, can help to minimise inequity by instituting changes within their own structures. These changes include: modifying services to ensure that they are accessible and acceptable to families from disadvantaged communities; understanding the problems faced by families living in poverty; considering the perceptions of families of their own needs; focusing on enabling individual families and communities to mobilise their strengths and resources; and establishing a genuine partnership in the care of their children., ${ }^{2,3}$

\section{THE SCHOOLS AS COMMUNITY PROJECT}

The Schools as Community Centres Project was established in 1995 in response to the Report of the Committee of Review of NSW Schools, ${ }^{9}$ which emphasised the important role that parents play in the education of their children. The report also emphasised that such factors as the health of children and the family have a major effect on the educational and lifelong outcomes for children. The Schools as Community Centres Project was designed to develop and trial models of effective and efficient interagency coordination to support families with children under five years of age. It was funded initially by the departments of Education and Training, Community Services and Health. The pilot project cost was approximately $\$ 600000$ over two years. The Department of Housing is now also contributing to the program costs and its expansion.

The project works with families with children aged under five to encourage and support them in their parenting role, actively promotes community involvement in providing services for children, and encourages and assists parents to access existing mainstream services in the community.

\section{PILOT SITES}

Four sites were chosen for the pilot the project: Redfern, Chertsey (Central Coast), Curran (Macquarie Fields) and Coonamble. These sites exhibit the features of 
disadvantaged communities, with indicators that suggest high levels of family stress. These four pilot sites provide various forms of support, education and assistance to some 500 families per week.

Each site consists of a 'community centre' that is staffed by a facilitator and is accommodated in spare classrooms on the premises of a local primary school. Schools were chosen to house the project because they are easily accessible by the community and there are benefits in developing early positive links between the home and school.

The facilitator is supported by a community-based advisory group and a local management committee. The management committee comprises the senior local representative of the participating government departments. It confirms the management plan for the site and approves collaborative strategies to support the project. The overall development of the project is overseen by a state inter-departmental steering committee which is responsible for briefing the Directors-General of the Departments on the progress of the project and emerging issues. The project is administered by the Department of Education and Training.

The facilitator consults the local community to identify service needs and local issues, targeting families with children under the age of five. The facilitator works with the community, advisory group and management group to plan collaborative responses to address these needs. The project provides opportunities for agencies to share information and plan on a local, collaborative basis.

Services developed through the project are largely preventive, with a strong focus on the health, welfare and development of young children. As the project has developed, it has become apparent that a core group of support services - for example, play groups, parenting information and groups, transition-to-school programs, information days and inter-agency forums to support workers - are needed at all four sites. A strength of the project is its ability to be tailored to each community's needs as initiatives are developed to reflect local priorities.

\section{EVALUATION OF THE PROJECT}

A formal evaluation of the project after the first two years demonstrated that it had successfully met its objectives. ${ }^{10}$ The Evaluation Report identified the following successes:
- community centres have developed strong links with their local communities and have initiated a large number of services, workshops, forums and other activities in response to community needs

- the centres have facilitated inter-agency communication, cooperation and collaboration

- families have felt supported in their parenting role; the centres are valued by parents as a source of information about, and referrals to, services

- children are being prepared effectively for school

- the project is contributing to the children's health and well-being

- a school community centre enhances the school's image

- people are developing positive perceptions of their community.

The Evaluation Report details the factors that are key to the success of the project as:

- a local approach

- the choice of facilitator

- the community centres being properly accommodated and resourced

- local management and advisory committees

- a community development approach

- consultation preceding the decision to locate a school community centre

- the project structure.

\section{HEALTH OUTCOMES}

The following health outcomes have been achieved:

- The level of age-appropriate immunisation has improved at all four sites.

- there is completion of the recommended child health surveillance and screening programs and attendance at referral appointments

- home visiting programs have been developed

- from the perspective of a broader view of health, there have been major gains in school readiness, attendance at school and community development

- there is improved inter-agency cooperation

- the project has been successful in promoting access to services for disadvantaged groups, including Aboriginal families and communities. 
This project is a whole-of-government initiative which provides an appropriate facility for developing many health programs, for example, interventions to improve nutrition, prevent behavioural disorders, child abuse and domestic violence.

Poverty is increasingly being identified as a significant determinant of health outcomes. In addressing these issues there is a need to develop strategies based on a broad perspective of health. The Schools as Community Centres Project is a successful example of a such a strategy. Due to its success, the Directors-General of participating departments have now endorsed the expansion of the project to two new sites in 1999: Kempsey (mid-north coast) and Bathurst (mid-western NSW).

\section{REFERENCES}

1. Mathers C. Health differentials among Australian children. Australian Institute of Health and Welfare, Health Monitoring Series no 3. Canberra: Australian Government Publishing Service, 1995.

2. Reading R. Poverty and the health of children and adolescents. Arch Dis Child 1997; 76: 463-467.

3. Spencer N, Graham H. Children in poverty. Lindstrom B, Spencer N, eds. Social paediatrics. Oxford University Press. 1995.
4 Birrell B, Maher T, Rapson V. Welfare dependance in Australia. People and place 1997; 5(2): 68-77.

5. Jolly DL, Nolan T, Moller J, Vimpani G. The impact of poverty and disadvantage in child health. J Paediatr Child Health 1991; 27: 203-217.

6. Weatherburn D, Lind B. Social and economic stress, child neglect and juvenile delinquency. NSW Bureau of Crime Statistics and Research, Attorney-General's Department, Sydney: 1997.

7. Kitzman H, Olds DL, Henderson CR, Hanks C, Cole R, Tatelbaum MD, McConnochie KM, et al. Effect of prenatal and infancy home visitation by nurses on pregnancy outcomes, childhood injuries and repeated childbearing: A randomized controlled trial. JAMA 1997. 278(8): 644-652.

8. Olds DL, Eckenrode J, Henderson CR, Kitzman H, Powers $\mathrm{J}$, Cole R, et al. Long term effects of home visitation on maternal life course and child abuse and neglect: Fifteen-year follow-up of a randomized trial. JAMA 1997; 278: 637-643.

9. The Report of the Committee of Review of New South Wales Schools. Sydney: NSW Government Printing, 1989.

10. Social Systems and Evaluation (Perth). Evaluation Report: Interagency Schools as Community Centres. Sydney: Department of Education and Training, 1997. it 